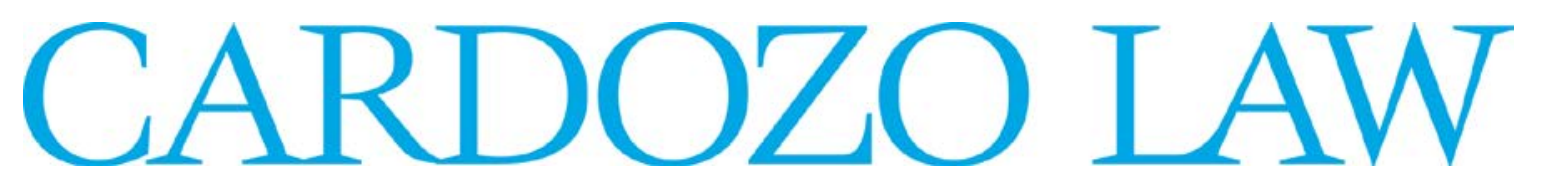

Benjamin N. Cardozo School of Law · Yeshiva University Jacob Burns Institute for Advanced Legal Studies

March, 2013

Faculty Research Paper No. 387

\title{
Two Enduring Lessons from Elinor Ostrom
}

Journal of Institutional Economics (forthcoming 2013)

Brett M. Frischmann

Professor of Law \& Director, Cardozo Intellectual

Property and Information Law Program

Benjamin N. Cardozo School of Law

55 Fifth Avenue, Room 1004

New York, NY 10003

(212) 790-0859 (phone)

frischma@yu.edu 


\title{
Two Enduring Lessons from Elinor Ostrom
}

\author{
Brett M. Frischmann ${ }^{1}$ \\ Benjamin N. Cardozo School of Law \\ Yeshiva University \\ New York, NY \\ frischma@yu.edu
}

\begin{abstract}
:
This article is a tribute to Elinor Ostrom. It explores two enduring lessons she taught: a substantive lesson that involves embracing complexity and context, and a methodological lesson that involves embracing a framework-driven approach to systematic, evolutionary learning through various interdisciplinary methodologies, theories, and empirical approaches.

First, I discuss Ostrom's work on environmental commons. I illustrate the two lessons through a discussion of the tragedy of the commons. Next, I explain how the two lessons play a significant role in recent efforts to extend Ostrom's work on environmental commons to knowledge/cultural commons. I draw a parallel between the tragedy of the commons allegory and the free rider allegory, and show how many of the problems Ostrom explored in the environmental context are manifest in the cultural environmental context. I discuss an ongoing research project that follows the path that Ostrom blazed and systematically studies commons in the cultural environment.
\end{abstract}

$* * * * * * * * * * * * * * * * * * * * * * * * * * * * * * * *$

Elinor Ostrom taught many lessons, as an amazing mentor, teacher, scholar, and human being. She had a profound influence on me, and I am honored to offer this tribute to her.

Like many others, I was inspired by Ostrom's design principles for natural resource commons and the demonstrated feasibility of community-based management for shared resources, and I tried to follow her lead. In fact, my first academic talk was about lessons from the literature on environmental commons that map to the study of other types of resource commons, such as information and Internet commons. I will return to the theme of that talk here. I will not discuss her theoretical or empirical contributions as such; many others have done so and will continue to do so, and for good reason. Instead, I will discuss two enduring lessons Ostrom taught about social science research. ${ }^{2}$

The two lessons can be summarized as follows:

\footnotetext{
${ }^{1}$ The author wishes to thank the editor-in-chief, two anonymous referees, Michael Burstein, Daniel Cole, Michael Madison, Al Roundtree, Charles Schweik, Alex Stein, and Katherine Strandburg for their constructive comments and suggestions. The usual disclaimer applies.

2 Throughout this article, I refer to contributions made by Ostrom and do not list all of her many collaborators or people who also made related contributions. But I want to be clear that she collaborated with many others and she readily acknowledged the independent contributions of many others working on similar issues.
} 
Substantive Lesson: Embrace complexity and context-or simply, reality; avoid distorting reductionism and overstated gains from simple models.

Methodological Lesson: Embrace systematic, evolutionary learning through various interdisciplinary methodologies, theories, and empirical approaches, including case studies; be aware of, and try to avoid, path dependencies from disciplinary or methodological blinders.

The first lesson leads to the second. Anyone can say that one should embrace complexity and study reality, and many people do. What makes Elinor Ostrom incredibly special is that she worked tirelessly to develop a robust framework for doing it, and she did it, time and again, and in a collaborative way that built an international interdisciplinary community.

In Part I, I discuss Ostrom's work on environmental commons. I illustrate the two lessons in the environmental context with a discussion of the tragedy of the commons. Ostrom's theoretical and empirical contributions probably are best recognized in the environmental context. Her contributions extend much further, as the Nobel Prize Committee recognized when it awarded her the 2009 prize along with Oliver Williamson. Still, there is plenty of work to be done in exploring and extending her contributions in other contexts. In Part II, I focus on that exploration and explain how the two lessons play a significant role in recent efforts to extend Ostrom's work on environmental commons to knowledge/cultural commons. I draw a parallel between the tragedy of the commons allegory and the free rider allegory, and then show how many of the problems Ostrom identified and explored in the environmental context are manifest in the cultural environmental context. I briefly discuss an ongoing research project that aims to follow the path that Ostrom blazed and systematically study commons in the cultural environment.

\section{Two Lessons from Ostrom's Work on Environmental Commons}

Elinor Ostrom's pioneering work challenged the notion that rational human beings would be helplessly trapped in social dilemmas. Much of her work focused on environmental commons and confronted the then-dominant and still powerful concept of the tragedy of the commons.

The term "commons" generally conjures up the notion of a shared community resource, such as a public park or a common pasture. The term gained considerable notoriety among economists, political scientists, and other social scientists after the publication of Garrett Hardin's essay The Tragedy of the Commons in Science (1968). Hardin (1968: 1244) described the tragedy of the commons as follows:

Picture a pasture open to all. It is to be expected that each herdsman will try to keep as many cattle as possible on the commons. .... As a rational being, each herdsman seeks to maximize his gain. Explicitly or implicitly, more or less consciously, he 
asks, "What is the utility to me of adding one more animal to my herd?" This utility has one negative and one positive component.

1) The positive component is a function of the increment of one animal. Since the herdsman receives all the proceeds from the sale of the additional animal, the positive utility is nearly +1 .

2) The negative component is a function of the additional overgrazing created by one more animal. Since, however, the effects of overgrazing are shared by all the herdsmen, the negative utility for any particular decision-making herdsman is only a fraction of -1 .

Adding together the component partial utilities, the rational herdsman concludes that the only sensible course for him to pursue is to add another animal to his herd. And another; and another.... But this is the conclusion reached by each and every rational herdsman sharing a commons. Therein is the tragedy. Each man is locked into a system that compels him to increase his herd without limit-in a world that is limited. Ruin is the destination toward which all men rush, each pursuing his own best interest in a society that believes in the freedom of the commons. Freedom in a commons brings ruin to all. ${ }^{3}$

Hardin's formulation has been the subject of extensive analysis and critique. At its core, the tragedy of the commons allegory illustrates a standard externality problem - each individual rationally maximizes his or her private welfare without accounting for external costs, i.e., the costs imposed on others. ${ }^{4}$ Avoiding tragedy seems to require collective action to manage use of the shared resource. Simply put, unconstrained consumption is not sustainable, and thus, constraints must be introduced if the resource is to be sustained.

What should the constraints consist of? Hardin recognized two (top-down) solutions: government regulation and privatization. Government can constrain consumption by directly managing or regulating use of the shared resource. Alternatively, government can establish a system of private property rights delineating ownership of the resource. The former presumes that the government will take into account the aggregate effects and manage use of the resource efficiently over time, and the latter presumes that well-defined private property rights will facilitate market exchanges and lead to an efficient allocation of access and use rights, and consequently, efficient management of the resource over time (Demsetz, 1967). Both approaches eliminate the commons; no longer do commoners freely choose for themselves how to manage a shared resource, for such freedom, Hardin claims, "brings ruin to all." Both approaches rely on collective action through government to introduce constraints. The approaches differ substantially in terms of the manner in which ongoing (month-to-month, day-to-day, minute-to-minute) resource allocation decisions are made.

\footnotetext{
${ }^{3}$ I include the block quote because it is useful to see what Hardin actually said. Paraphrasing Hardin often leads to adjustments that obscure or improve Hardin's simple story.

${ }^{4}$ In Coasian terms, it is a joint cost problem (Coase, 1960).
} 
The tragedy of the commons allegory became the starting point for examining common pool resource problems and solutions. Many analysts assumed the tragedy of the commons model described a normal problem (at least for common pool resources) and a binary solution set followed: To avoid tragedy, society must turn to government command-and-control (micromanagement) or private property-enabled markets. Economists, political scientists, and many others analyzed and debated how well these two types of regulatory solutions work. Will command-and-control regulation by government lead to efficient outcomes or would society be better off relying on private ordering by markets?

Elinor Ostrom challenged the entire enterprise at its roots by asking two foundational sets of questions: First, how well does the tragedy of the commons allegory describe reality? Is it a useful theory for making predictions about real-world behavior of individuals sharing common pool resources? Does it describe a normal or exceptional situation? Does it provide a useful basis for choosing or designing regulatory solutions? Second, does the binary choice between government command-and-control regulation and private property-enabled markets reflect the full range of options? Are there alternative (bottom-up) institutions and/or means for collective action?

Critically, the two sets of questions are related, particularly when one begins with the tragedy of the commons allegory. Hardin blurred resource system with resource management. In his allegory, the shared resource system is the pasture, and open access sharing among herders is the resource management or governance regime. As did many social scientists, Hardin made a series of assumptions with respect to both resource and resource management that limit the generalizability of his allegory. As Ostrom (2007: 15183) explained:

Hardin envisioned a pasture open to all in which each herder received a direct benefit from adding animals to graze on the pasture and suffered only delayed costs from overgrazing. Translating his metaphor into a theory requires five assumptions:

(i) the resource system is a pasture;

(ii) no governance system is present related to the resource system;

(iii) the mobile individual resource units (the animals grazing on the pasture) can be identified and are the property of their owners and, when fattened, can be sold for cash;

(iv) a sufficient number of users, given the size of the pasture, are using the pasture to adversely affect its long-term productivity; and

(v) the resource users independently make decisions to maximize their own short-term returns.

These five assumptions ... lead to a theoretical prediction of very high harvesting of the pasture grasses and severe overharvesting or destruction of the ecological system.

$* * *$ 
Situations characterized by these assumptions, in which individuals independently make anonymous decisions and primarily focus on their own immediate payoffs, do tend to overharvest open-access resources. Researchers have repeatedly generated a "tragedy of the commons" in experimental laboratories when subjects make independent and anonymous decisions in a common-pool resource setting.

Making one small change ... in the structure of laboratory experiments, a change that is predicted by game theory to make no difference in the predicted outcome, has repeatedly had major impacts on interactions and outcomes. Simply enabling subjects to engage in face-to-face communication between decision rounds enables them to approach socially optimal harvesting levels rather than severely overharvesting the commons. In the face-to-face discussions, participants tend to discuss what they all should do and build norms to encourage conformance. ${ }^{5}$

Note that when the assumptions hold and fully describe the resource setting, the theory's predictions may be useful. But this is exceptional. Reality is considerably more complex. The tragedy of the commons allegory rarely describes shared resource settings in a sufficiently complete manner as to qualify as a useful theory for making predictions or prescribing regulatory solutions. More is needed.

Of course, it may be convenient to work within the confines of the allegory or model-and perhaps to assume that reality conforms to those confines-because doing so makes analysis tractable and leads to a well-defined problem and possible solutions to compare and evaluate. But this is a fundamental mistake and an example of distorting reductionism. It can lead the analyst to miss what is most important and focus on what is least relevant.

As Ostrom (2007) explained in the quote above, a slight change, which takes you outside the confines of the model, gives rise to solutions that completely escaped attention and would not be predicted to be relevant. Relaxing one of the assumptions, or just recognizing that some other factor is relevant to the situation, can change everything; cooperation to avoid tragedy becomes theoretically feasible without resort to one of the two "solutions." As is now well understood in the field of institutional economics generally, community management, social norms, and other

\footnotetext{
${ }^{5}$ Ostrom (2000) also critiqued reliance on the rational actor model when analyzing collective action and social dilemmas. After establishing a series of "well-substantiated facts" about human behavior based on extensive fieldwork: "I believe that one is forced by these well-substantiated facts to adopt a more eclectic (and classical) view of human behavior" (Ostrom, 2000: 141). She developed a "second-generation model of rationality" in which humans are "complex, fallible learners who seek to do as well as they can given the constraints that they face and who are able to learn heuristics, norms, rules, and how to craft rules to improve achieved outcomes" (Ostrom, 1998: 9). The second-generation model of rationality predicts that reciprocity, reputation, and trust as "core relationships" can lead to increased net benefits (Ostrom, 1998: 13). This theoretical model identifies "individual attributes" that are particularly important in explaining behavior in social dilemmas: these attributes include "[1] the expectations individuals have about others' behavior (trust), [2] the norms individuals learn from socialization and life's experiences (reciprocity), and [3] the identities individuals create that project their intentions and norms (reputation)" (Ostrom, 1998: 14).
} 
institutional arrangements are relevant solutions that can and often do outperform government regulation and market regulation.

Ostrom's contribution goes well beyond recognizing the limits of models and acknowledging what is theoretically feasible. While it is important to understand Ostrom's concerns about model-induced myopia, it is equally if not more important to appreciate how she responded to those concerns. In Governing The Commons: The Evolution Of Institutions For Collective Action, for example, Ostrom (1990) explained how models such as the tragedy of the commons lead to myopic analysis of solutions and policy prescriptions. She suggested that neither the Leviathan (government regulation) nor Privatization (market regulation) is a panacea, and that model-induced myopia leads analysts to ignore alternative institutional arrangements that may be more effective tools for governance. But that is merely the beginning-literally, chapter one of the book (Ostrom, 1990).

Ostrom was a scientist. Her response to concerns about model-induced myopia was to do the scientific work of systematically studying actual resource systems and governance institutions.

Over decades, Ostrom demonstrated through a rich empirical program how self-organized community governance often is an effective alternative for a wide range of shared resources. In some contexts, communities can and do solve tragedy of the commons, collective action, and other related resource management problems without (turning to) government regulation or marketdriven allocation as a panacea. They do so in a variety of ways, often relying on informal mechanisms for coordinating behavior. Community solutions do not always succeed or always fail; they sometimes succeed and sometimes fail. "The temptation to seek out regulatory panaceas based on universal models, whether through private property, state action, or even notions of community, must be resisted in favor of a more nuanced approach" (Madison, Frischmann and Strandburg, 2010a: 676). Context matters.

Recognizing that people sometimes cooperate effectively and build institutions to enable sustainable shared use of common pool resources opened up the "solution space" and focused scholarly attention on complexity, context, communities, and institutions. This broader field of vision not only brought informal institutions into view and encouraged their systematic study, but it also improved our understanding of formal institutions by revealing the many different ways that government, market, and community institutions depend on each other to be successful. ${ }^{6}$ And it yielded two significant lessons, one substantive and one methodological.

\section{Ostrom's Substantive Lesson:}

\footnotetext{
${ }^{6}$ As explored in a recent book, Ostrom's vision allows us to appreciate that government regulation of shared environmental resources does not replace or eliminate the commons altogether-for that would be the true tragedy! Rather, in many cases, government regulation constructs a semi-commons where a narrow range of resource users/uses are constrained in order to sustain "freedom in the commons" for a wide range of other resource users/uses (Frischmann, 2012).
} 
Embrace complexity and context-or simply, reality. There is tremendous value in systematically studying actual contexts that present potential tragedies and institutional arrangements aimed at averting tragedies.

Be wary of model-induced myopia, supposed panaceas, and binary thinking. The deep problem with Hardin's tragedy of the commons allegory is not the allegory itself or its translation into a model or even a theory about how people might externalize costs in specific settings. The deep problem is the myopia that the model induced and the binary government-or-market thinking that followed. We consistently make the mistake of thinking in binary terms, individual or social, private or public, market or government. This leads to great distortions in our perceptions about the world and the plans we make. Reality is much more complicated.

Standing alone, this lesson may be underwhelming, or perhaps even offensive to the scholar. You might be thinking, "This is not a lesson. We all know that studying reality beats studying fictitious scenarios that do not match reality." Naturally, the next question is how should one go about studying reality? This leads to the second lesson. ${ }^{7}$

\section{Ostrom's Methodological Lesson:}

Embrace systematic, evolutionary learning through various interdisciplinary methodologies, theories, and empirical approaches, including case studies. There is tremendous value in a research framework that facilitates such learning while itself being subject to adaptation and refinement over time.

Ostrom did not presume community based institutions were successful or ubiquitous. Community based institutions required systematic study. To facilitate research on these institutions across diverse resource systems, Ostrom worked for decades on developing a scientific approach to studying and evaluating institutions. She devoted incredible energy to methodology, bridging disciplines, and enabling systematic, collaborative social science.

To systematize research, she developed the Institutional Analysis and Development ("IAD") framework. ${ }^{8}$ It encourages interdisciplinary research and seeks to avoid path dependencies from

\footnotetext{
${ }^{7}$ The risk of model-induced myopia that Ostrom identified also provides a strong basis for taking a pluralistic approach to thinking about, and teaching, economics, especially if one cannot go out and study reality as Ostrom did.

${ }^{8}$ I discuss the IAD framework as a prominent example, but the reader should understand that Ostrom extended her ideas to the development of a more complex framework for the analysis of Social-Ecological Systems (Ostrom, 2009). Moreover, even when applying the IAD framework, the specific context shaped the research protocols. For example, as reported in Hayes and Ostrom (2005), Ostrom and colleagues associated with the Center for the Study of Institutions, Population, and Environmental Change (CIPEC) and the Workshop in Political Theory and Policy Analysis, both at Indiana University, developed a complex question-based framework tailored for analyzing forests: "Our research team spent two years developing a series of ten protocols," that "enable scholars to examine the impact of diverse ways of owning and governing forests (such as individual ownership, joint ownership by a
} 
disciplinary or methodological blinders, problems akin to the model-induced myopia discussed above. The IAD framework structures a common set of research questions to apply across diverse contexts. Ostrom (2005: 28-29) explained the relationships between a research framework, theories, and models:

The development and use of a general framework helps to identify the elements (and the relationships among these elements) that one needs to consider for institutional analysis. Frameworks ... provide the most general set of variables that should be used to analyze all types of settings relevant for the framework. . .

The development and use of theories enable the analyst to specify which components of a framework are relevant for certain kinds of questions and to make broad working assumptions about these elements. Thus, theories focus on parts of a framework and make specific assumptions that are necessary for an analyst to diagnose a phenomenon, explain its processes, and predict outcomes. . . - Microeconomic theory, game theory, transaction cost theory, social choice theory, public choice, constitutional and covenantal theory, and theories of public goods and common-pool resources are all compatible with the IAD framework

The development and use of models make precise assumptions about a limited set of parameters and variables. Logic, mathematics, game theory models, experimentation and simulation, and other means are used to explore the consequences of these assumptions systematically on a limited set of outcomes. Multiple models are compatible with most theories. ...

The framework-driven approach is functionalist. It seeks to integrate theoretical and empirical research in coherent manner. Critically, Ostrom did not reject theories or models, but instead embraced the idea that different theories and models could work better for some observed phenomena than for others. ${ }^{9}$ The IAD framework aims to systematize research efforts by facilitating "a more rigorous evaluation by matching and testing of theories and models with observed phenomena, and most generally, enable learning over time" (Madison, Frischmann and Strandburg, 2010a: 678). It depends heavily on empirical data, and consequently, on a systematic approach to gathering data.

The IAD framework identifies the most general set of variables that should be used to analyze all types of settings relevant for the framework and divides the investigation of such variables into groups. ${ }^{10}$ The first group is exogenous variables and includes biophysical characteristics, community attributes, and "rules-in-use" (or governance mechanisms). With respect to the

community, and different forms of government ownership) on investment, harvesting, protection, and managing activities and their consequences on forest conditions, including biodiversity" (Hayes and Ostrom, 2005: 603-604).

${ }^{9}$ She did reject the idea of a one-size-fits-all theory.

${ }^{10}$ The following four paragraphs are adapted from Madison, Frischmann and Strandburg (2010a: 678-680). 
analysis of a particular situation, these attributes of a commons are fixed. In the case of the lobster fishery, for example, these attributes might include the relevant biological characteristics of lobsters, such as the rates at which they age and reproduce; attributes of the community of fishermen, such as the proximity in which they live to others, the existence of familial relationships, and the skill sets needed for lobster fishing; and the rules-explicit or informalthat govern fishing.

The second group is the "action arena," which "refers to the social space where participants with diverse preferences interact, exchange goods and services, solve problems, dominate one another, or fight (among the many things that individuals do in action arenas)" (Ostrom, 2005: 14). In other words, the "action arena" is the context in which the exogenous variables combine in particular instances, leading over time to observed patterns of interactions and outcomes.

Ostrom's work emphasizes the diversity of possible combinations of exogenous variables that determine what actually happens in particular instances and, hence, the outcomes that result. The rules governing lobster fishing contribute to the activity's long-term sustainability, for example, but the patterns of interaction actually observed depend on the richness of the particular environment for lobsters, the degree to which rules are actually enforced, seasonal factors such as weather, and interaction with outside influences such as pollution and the state of the larger economy. Understanding the observed success or failure of a commons enterprise such as a lobster fishery may require accounting for all of these factors, even though it may turn out that outcomes are relatively impervious to some of them.

The foundation of the framework-driven analysis is structuring questions in clusters about the exogenous variables, the action arena, and the patterns of interactions and outcomes. This approach aims to systematize data gathering across complex, diverse phenomena while remaining amenable to diverse disciplinary perspectives and empirical methodologies.

One interesting aspect of the IAD framework is its accommodation of and heavy reliance on case studies. Case studies are an important component to the research program because case studies provide rich, detailed descriptions of institutional arrangements in context. In addition, case studies provide feedback for the research framework itself. ${ }^{11}$ Of course, case studies also slow

\footnotetext{
${ }^{11}$ To implement the IAD framework, Ostrom and her collaborators employed a three-pronged approach: First, they engaged in a broad range of case studies of natural resource commons to form a basis for a bottom-up practice-based taxonomy of successful and unsuccessful approaches to resource management. Second, they developed a framework, based on the initial case studies, for identifying the variables that are significant in determining the success or failure of a commons enterprise and of the viability of institutions in particular contexts. Third, they preserved flexibility in their framework so that it could be adapted and revised in response to learning derived from the case studies. Based on the information obtained by applying their framework to structured case studies, they developed theories and models for particular commons situations, designed experiments to test those theories, and advanced a set of design principles for successful natural resource commons (Madison, Frischmann and Strandburg, 2010a: 676-677).
} 
things down, making the empirical work more laborious, contentious, and incremental. Arguably, this is a virtue. Good (social) scientific research often takes time. A framework driven approach is particularly attractive for studying the complex interactions between ecological and social (institutional) systems because of the many different disciplines and methodologies that must be brought to bear if progress is to be made (Ostrom, 2009).

Ostrom's embrace of complexity goes further than studying reality and adopting a framework to accommodate different theories and methodologies. She also embraced collaboration among different people, disciplines, and cultures. She worked hard to "establish[] a common ground in the fractured academic world of the natural and social sciences" (Becker and Ostrom, 1995: 114). Her work was forcefully interdisciplinary, and throughout her career, she called on various disciplines to remove their disciplinary blinders. In her Presidential Address to the American Political Science Association, for example, Ostrom called for expansion of the "type of research methods regularly used in political science" and suggested that more understanding is required across the social and biological sciences (Ostrom, 1998).

Ostrom recognized that studying commons requires a kind of commons of its own, an interdisciplinary community for sharing skills, knowledge, research, and experience. So she built one. ${ }^{12}$ With "an ad hoc group of scholars including political scientists, anthropologists, economists, historians, and natural resource managers" she founded the International Association for the Study of the Commons. ${ }^{13}$ She was the first President of the IASC. The IASC's three goals are

1. to encourage exchange of knowledge among diverse disciplines, areas, and resource types;

2. to foster mutual exchange of scholarship and practical experience; and

3. to promote appropriate institutional design.

In pursuit of these goals, the IASC hosts major international conferences, publishes The Commons Digest and the International Journal of the Commons, and engages in many other activities that promote knowledge sharing and build social capital and connections among those concerned with commons. ${ }^{14}$ Ostrom's legacy is most vividly seen in the thousands of people around the world, in many different disciplines and professional settings, who consider themselves a part of the research commons she helped construct.

\footnotetext{
${ }^{12}$ Actually, she built many. Of particular note, with her husband Vincent Ostrom, also a renowned political scientist, she founded the Workshop in Political Theory and Policy Analysis. The Workshop is an autonomous research center at Indiana University dedicated to the interdisciplinary, collaborative, and comparative study of institutions (see Indiana University Bloomington, 2008). In honor of the couple, IU renamed the workshop, The Vincent and Elinor Ostrom Workshop in Political Theory and Policy Analysis.

${ }^{13}$ See International Association for the Study of the Commons (2012b).

${ }^{14}$ For more details, see International Association for the Study of the Commons (2012a).
} 


\section{Applying Ostrom's Lessons to Commons in the Cultural Environment (or Knowledge Commons)}

Ostrom may be most well known among environmental scholars, but her lessons extend well beyond natural environmental resources. Here, I focus on commons in the cultural environment. This label sometimes confuses people; so let me briefly explain. I use the term "cultural environment" to refer to the various cultural, intellectual, scientific and social resources/systems that we inherit, use, experience, interact with, change, and pass on to future generations. Commons in the cultural environment thus refers to information commons, science commons, cultural commons, data commons, and other types of intellectual resource commons (Frischmann, 2012: 253-314; Madison, Frischmann and Strandburg, 2010a; Frischmann, 2007). As shorthand, I and others sometimes refer to these as knowledge commons (Hess and Ostrom, 2005). There are good reasons for casting a wide net and grouping information, science, knowledge, culture, data, and so on together. For brevity, I may refer to one member or another, but the analysis that follows applies to all.

It turns out that intellectual resources have their own "tragedy of the commons"-type allegory. It is usually invokes the "free rider" as the selfish actor. Replace Hardin's pasture with an intellectual resource - for example, an idea-and consider what happens when the resource is openly accessible to all. Everyone who can profitably make use of the idea will do so, as much and as often and in whatever manner suits them. "So what?" you may ask, "Where is the tragedy in that? There is no depletion and so there is no ruin." Ideas are public goods, not common pool resources; ideas are consumed nonrivalrously; they have infinite capacity and are not congested or depleted. Unconstrained consumption does not seem to pose a problem. However, there is a catch. We posited an existing idea. The trouble is that, unlike a pasture, ideas are products of human intellect; they must be created and often require investment. Unconstrained consumption of intellectual resources presents a risk for potential investors because it may be difficult to recover a sufficient return from those who consume the idea. We might call these consumers "free riders" because they are getting a free ride on the idea creator's investment. ${ }^{15}$ The result of free riding is not too much consumption; rather, it is consumption without payment, and that might lead to underproduction of the shared resource, that is, the idea.

When viewed from a dynamic perspective, tragic underproduction of intellectual resources appears to be an inevitable social dilemma so long as consumption is unconstrained. In fact, the underlying problem can be modeled to look exactly like Hardin's tragedy of the commons

\footnotetext{
${ }^{15}$ There are a number of complications. First, even if consumers pay something to contribute to the production of the public good, they may behave strategically and misrepresent their actual preferences with the objective of letting others bear a greater proportion of the costs (Samuelson, 1954). This is a variant of the free-riding problem discussed in the text, but it does not correspond to ex post opportunism and is not solved by exclusion via intellectual property rights (Frischmann, 2012: 265). Second, some consumers (competitors) who obtain access to the resource can share it with others at a marginal cost of zero. Such sharing may fuel competition but undercut investors' ability to secure a return.
} 
allegory. At its core, the free rider allegory also illustrates a standard externality problem — each individual rationally maximizes his or her private welfare without accounting for external costs. In this context, the social costs encompass the risk to investment and resulting underproduction of public goods over time. Again, the model can be easily translated into a classic collective action problem. Avoiding tragedy seems to require collective action to manage use of the shared resource. Simply put, unconstrained consumption appears unsustainable. A solution is needed.

In remarkable parallelism, many analysts simply assume the free rider allegory describes a normal (rather than exceptional) problem. Again, a binary solution set naturally follows: To avoid tragedy, society must turn to production subsidized by government or to intellectual property-enabled markets. Government subsidization does not involve introducing constraints on consumption. Instead, the underproduction problem is dealt with head on. Government directs funds to research activities that yield intellectual resources and thus investment risks no longer matter. These intellectual resources can be shared openly and freely. On the other hand, intellectual property rights, such as patents and copyrights, lower the costs of exclusion, enable transactions, and mitigate the risk to investment posed by free riders. Intellectual property rights thus enable markets to function more effectively in supplying intellectual resources. Both approaches rely on collective action through government but differ substantially in terms of the manner in which resource allocation decisions are made. ${ }^{16}$

The free rider allegory, like the tragedy of the commons allegory, has played a powerful role in shaping the relevant discourse, policy, and law (Lemley, 2005). It figures prominently in the classroom (textbooks), courtroom (legal opinions), and halls of Congress (political debate).

Yet we should focus on reality and be wary of powerful allegories. Following Ostrom, we should ask two foundational sets of questions: First, how well does the free rider allegory describe reality? Is it a useful theory for making predictions about real-world behavior of individuals? Does it describe a normal or exceptional situation? Does it provide a useful basis for choosing or designing regulatory solutions? Second, does the binary choice between government subsidization and intellectual property-enabled markets reflect the full range of options? Are there alternative institutions and/or means for collective action?

Free riding - the act of freely using resources generated by another person without payment or even authorization - is normal. As I (Frischmann, 2012: 161) argued recently:

free riding is pervasive in society and a feature, rather than a bug, of our economic, cultural, and social systems. There are innumerable examples of free riding in society, and there is little reason to think that such behavior is inefficiently suppressing investment incentives systematically throughout society. Rather, idea diffusion and competition,

\footnotetext{
${ }^{16}$ For a discussion of how government and market resource allocation decisions depend on fundamentally different demand signals and evaluation, and how these differences impact the cultural environment, see Frischmann (2012: 109-110, 253-314).
} 
among other important social processes, depend significantly on free-unauthorized, unlicensed, unapproved and often unpaid - riding.

The more difficult question is whether free riding that involves intellectual resources systematically reduces incentives to invest in such resources. Does such free riding normally lead to a social dilemma? The claim that it does hinges on certain premises about the behavior of investors. How does free riding impact actual people who invest time, money, effort, or other resources to produce intellectual resources? Does the risk of free riding diminish their incentives to invest? ${ }^{17}$

Whether private incentives are in fact inefficiently suppressed by this risk depends on the type of investment, the intellectual resource in question, and the particular context. Many intellectual resources plainly are not subject to this particular concern, as evidenced by the fact that people consistently generate the resources without being disabled by concerns over misappropriation. In many situations, people make investments because the expected private benefits exceed their fixed costs, regardless of whether or not others free ride. Appropriating benefits through market exchange of the intellectual resource or some derivative product may not be relevant to the investor. For example, we engage in many intellectually productive activities because participation itself provides sufficient private benefits (Madison, Frischmann and Strandburg, 2010a; Frey, 2008: 35). Participation can be fun, intellectually stimulating, educational, service-oriented, among other things (Benkler, 2006; Schweik and English, 2012). Participation may not be effortless or free; it may require substantial investment. Regardless, the private value derived from participation may be sufficient, and external benefits conferred to others that use or consume the output (i.e., the intellectual resource) may be irrelevant to incentives to invest. ${ }^{18}$ Similarly, in many situations, people create, invent, and innovate because the anticipated returns from their own use of the results are sufficient to justify the investment. There is a rich literature on user innovation that demonstrates how many significant innovations result from users seeking to solve their own particular problems, needs, or curiosities (Von Hippel, 2006; Strandburg, 2009: 871-888). People often engage in such activities without disabling concern over free riding.

There are many other examples, but the point should be clear. Free riding does not necessarily reduce incentives to invest and does not inevitably lead to a social dilemma. Reality is considerably more complex than the free rider allegory suggests, and there is no good reason for systematically marginalizing the many situations in which free riding that involves intellectual resources does not reduce incentives to invest. Such myopia is inexcusable. The bottom line is

\footnotetext{
${ }^{17}$ If free riding does diminish incentives to invest, we would still need to investigate how and to what degree. Among other things, reducing free riding via intellectual property rights likely exhibits diminishing returns in terms of the impact on incentives. For further discussion, see Frischmann and Lemley (2007).

${ }^{18}$ Even if those benefits could be internalized, such internalization could potentially decrease incentives to invest and prove quite costly (Pink, 2010: 37; Amabile, 1996: 17; Benkler, 2006: 298; Frischmann and Lemley, 2007).
} 
that the allegory rarely describes shared resource settings in a sufficiently complete manner to qualify as a useful theory for making predictions or prescribing solutions. Much more is needed.

My hypothesis is that free riding negatively impacts investment incentives and leads to social dilemmas in only exceptional circumstances, but frankly, I do not have empirical evidence to test this hypothesis (nor does anyone else, to my knowledge). My hypothesis is based on anecdote and observation, as well as a broad conception of the relevant universe of free riding phenomena and circumstances (investment opportunities). Regardless, as noted above, I confidently claim that free riding is ubiquitous and often quite beneficial in the sense that it is an important feature of competition and idea diffusion in society, often generating positive externalities as free riders use ideas productively (Frischmann, 2012). Consequently, we must take care when prescribing solutions to solve supposed social dilemmas associated with free riding.

Even in situations where free riding reduces incentives to invest and a social "underproduction" dilemma arises, ${ }^{19}$ it turns out that there are many complications that are too easily overlooked. Ostrom's substantive lesson applies with equal force. First, there are no panaceas. Government subsidies and intellectual property rights are prominent means for addressing social dilemmas, but both "solutions" are far from perfect; both are incomplete and introduce their own complications, biases, and inefficiencies. ${ }^{20}$ Second, and more important for purposes of this article, there are many alternative solutions that people regularly employ to avoid tragedy. Commons in the cultural environment are an important set of alternatives that deserve systematic study (Hess and Ostrom, 2005).

Before proceeding, it is important to be clear about what I mean when I refer to commons; the concept is remarkably fluid and varies considerably in its usage across different disciplines. Here is how I use it:

Commons is an institutionalized community practice, a form of community management or governance. It applies to resources, and it involves a group or community of people, but the commons itself is not the resources, the community, a place, or a thing. Commons is the institutional arrangement of these elements. "The basic characteristic that distinguishes commons from noncommons is institutionalized sharing of resources among members of a community" (Madison, Frischmann and Strandburg, 2010b: 841). Critically, there is incredible variance among commons in terms of the types of resources and communities, and consequently, in terms of the institutions through which governance is practiced or implemented. Of course, there are various obstacles to sustainable sharing. The tragedy of the commons allegory highlights one, and the free riding allegory highlights another. In reality, communities can and often do overcome these and other obstacles through constructed as well as emergent

\footnotetext{
${ }^{19}$ The classic example of a context in which this dilemma arises is the pharmaceuticals industry (Burk and Lemley, 2009.)

${ }^{20}$ There is a rich literature that defies a brief summary.
} 
commons. $^{21}$ And yet, as Ostrom made clear, commons can and often do fail, and thus demand systematic study.

Commons in the cultural environment refers to the institutionalized community practice of sharing information, science, knowledge, data, and other types of intellectual and cultural resources. Many communities regularly share such resources and overcome concerns about free riding and other dilemmas. ${ }^{22}$

Most obvious may be research commons, given the importance of sharing and collaboration norms within scientific research communities (Reichman and Uhlir, 2003; Merton, 1973). Reichman and Uhlir (2003) examined scientific data commons, pressures on the "sharing ethos" within various scientific communities, and institutional means for reconstructing commons. Cook-Deegan and Dedeurwaerdere (2006) examined research commons in the life sciences and mapped out some of the relationships between the structure and function of the resource commons and the relevant community. The National Research Council of the National Academies sponsored an international conference in 2009 that explored microbial research commons. Participants examined how upstream microbial research inputs - microbial data, literature, and research materials_can be managed as a commons (Uhlir, 2011; Reichman, Dedeurwaerdere and Uhlir, forthcoming).

Madison, Frischmann and Strandburg (2010a) discussed the following less obvious examples: intellectual property pools, in which owners of patents in a technological domain license their patents to a common "pool" from which producers of complex products can obtain all of the permissions needed to make and sell goods that use the patents; open source computer software projects, which offer users of open source programs the ability to create and share modifications to the programs; ${ }^{23}$ Wikipedia, which offers users of this Internet encyclopedia the power to add to and edit its contents; the wire service for journalism operated by the Associated Press, which allows individual member media outlets the opportunity to publish work produced by other members; and "jamband" fan communities, which record, share, and comment on musical performances of their favorite groups - with the permission of the artists themselves. We mentioned additional examples, including medieval guilds, "the modern research university and

\footnotetext{
${ }^{21}$ The distinction between constructed and emergent commons arose in the exchange we had with Professors Wendy Gordon and Gregg Macey in the Cornell Law Review (Gordon, 2010: 735,n.14; Macey, 2010: 785-780; Madison, Frischmann and Strandburg, 2010b: 846-847).

${ }^{22}$ Some dilemmas arise from the traditional solutions to the free rider problem. For example, intellectual property rights can interfere with productive use of intellectual resources and deter investments in areas where investors perceive a threat of exclusive rights "blocking" utilization or further development. I will not explore the various dilemmas here, but I would like to make clear that commons are sometimes constructed to overcome problems created by intellectual property rights (e.g., avoiding a so-called anti-commons). Yet in other contexts, intellectual property rights are critical inputs for creating a commons and facilitating cooperation and joint production (e.g., open source software development projects, such as Linux) (Madison, Frischmann and Strandburg, 2010a).

${ }^{23}$ For a systematic study of open source software projects using the IAD Framework, see Schweik and English (2012).
} 
the departmental and disciplinary structures that lie within and above it," and the Request for Comments ("RFCs") series that defines the technical protocols of the Internet. During a conference hosted at New York University in 2011, scholars presented case studies that ranged from rare disease research consortia to recreational roller derby leagues.

There are many different commons in the cultural environment. Yet we know very little about them: How do such commons work? Where do they come from, what contributes to their durability and effectiveness, and what undermines them?

In the past decade, scholars in various disciplines have become interested in studying these types of commons, and some have begun case studies. However, their research too often is focused narrowly on the specific case or an isolated area, such as academic publishing or open source software, and fails to investigate the broader institutional questions and to appreciate the need for systematic analysis. $^{24}$ As a result, they tend to consider only a limited number of descriptive variables, which makes integration and learning from a body of case studies quite difficult.

Guided by Ostrom's methodological lesson and building on her IAD framework as well as her pioneering book with Charlotte Hess (Hess and Ostrom, 2005), Madison, Frischmann and Strandburg (2010a) developed a research framework to facilitate systematic study of commons in the cultural environment. The underlying nature and structure of the inquiry as well as the focus on complexity, context, communities, and institutions unites our project with her legacy. Nonetheless, we needed to adapt and extend the IAD framework to account for significant differences between commons in the natural environment and commons in the cultural environment. Most obvious, the resources are different, and as a result, the obstacles that must be overcome for institutionalized sharing to work are different. Thus, for example, the governance structures for commons in the cultural environment manage existing resources as well as production and integration of new resources. Another interesting complication is the complex role of legal institutions in delineating intellectual resources, for example, by defining what constitutes the expression in software that might be governed by open source software licenses. Notably, this complication raises resource boundary and corresponding resource management issues that are less salient for commons in the natural environment.

Madison, Frischmann and Strandburg (2010a) explored these and other differences extensively, and explained why the differences call for a series of inquiries specifically tailored to commons in the cultural environment. It turns out that the exogenous variables are more intertwined in this context because separating the managed resources from the attributes and rules-in-use of the community that produces them can be incredibly difficult, if not impossible in some

\footnotetext{
${ }^{24}$ This is not a critique of those scholars. The point is that someone carefully studying a particular information commons - say, a patent pool-may not appreciate - much less have the tools or incentives to observe, record, and evaluate - the many descriptive variables concerning the shared resources, community members, institutions, and context that would facilitate comparison with other commons in the cultural environment - say, other intellectual property pools, open source projects, online commons-based peer-production, jambands, and so on.
} 
contexts. Moreover, distinguishing outcomes from resources and community attributes is not always strictly possible, since the interactions of the participants in these commons are inextricably linked with the form and content of the knowledge output, which in turn is itself a resource for future production. At this stage, we have identified the most general set of variables that should be used to analyze all types of settings relevant for our framework and divided the investigation of such variables into groups of questions, summarized in the following abbreviated outline:

\section{Background Environment}

a. What is the background context (legal, cultural, etc.) of this particular commons?

b. What is the "default" status of the resources involved in the commons? Patented? Copyright? Open?

\section{Attributes of the Commons}

a. Resources

i. Identify all resources being pooled and how they are created or obtained

ii. Describe the characteristics of the resources, such as whether they are rival or non-rival, whether they are tangible or intangible, the technologies needed to create, obtain, or maintain them, and the technologies and skills required to use them

b. Community Members

i. Identify community members and describe their roles

ii. Describe the degree and nature of openness of the community with respect to each type of community member and the general public

c. Goals and objectives of the commons

i. Identify the goals and objectives of the commons

ii. Identify the history and narrative of the commons

\section{Governance}

a. What are the governance mechanisms of the commons (e.g., membership rules, resource contribution or extraction standards and requirements, conflict resolution mechanisms, sanctions for rule violation)

b. Who are the decision-makers and how are they selected?

c. What are the institutions that govern decision-making?

d. What informal norms govern the commons?

e. How do nonmembers interact with the commons? What institutions govern those interactions?

f. What legal structures (including intellectual property rules, subsidies, contract and licensing law, antitrust provisions) govern the functioning of the commons? 


\section{IV.Patterns and Outcomes}

a. What benefits are delivered to members and to others (including innovations and creative output, production, sharing, and dissemination of those innovations and output to a broader audience, and social interactions that emerge from the commons?)

b. What costs and risks are associated with the commons, including, for example, any negative externalities?

Essentially, these clusters of issues guide more detailed inquiry. Case studies across disciplines and reviews of existing literature that address commons in the cultural environment will help specify relevant attributes within each cluster. We are developing a coding manual for case studies, and we expect the framework to evolve further as researchers apply it to specific case studies. This process is currently underway.

Taking another page from Ostrom's lesson book, we have begun to build an international and interdisciplinary research community. Many case studies are underway; more are being planned. It may be a while before we have any major scientific findings to report; it may be slow-going, laborious, and incremental. But that is fine because, as Ostrom showed us, good (social) scientific research often takes time.

\section{Conclusion}

Elinor Ostrom received the Nobel Prize because of her groundbreaking and path-setting research. Many people are only starting to realize and understand the import of her theoretical and empirical contributions to institutional economics. These contributions will continue to shape research and education in economics, political science, law, and other disciplines concerned with institutions that shape collective action and community governance of shared resources.

The two enduring lessons I highlighted in this article are more basic. They derive from her scientific approach to research, and her corresponding demand for rigorous, systematic inquiry. I am grateful to have learned these lessons, as I believe they provide a basis for continuing her work and extending it to other contexts. Commons in the cultural environment are one example, but there are others-e.g., infrastructure commons and privacy commons. Simple models of social dilemmas, as well as binary thinking about solutions (government versus market), are legion.

I am grateful to have known Elinor Ostrom and to have learned all that she taught me. She is missed, but she remains present in the minds and hearts of the many people she influenced, as her dedication and insights inspire and fuel future work. 
References

Amabile, T. M. (1996), Creativity in Context: Update To The Social Psychology Of Creativity, Boulder, CO: Westview Press.

Becker, C. D. and E. Ostrom (1995), "Human Ecology and Resource Sustainability: The Importance of Institutional Diversity”, Annual Review of Ecology and Systematics, 26: 113-133.

Benkler, Y. (2006), The Wealth of Networks: How Social Production Transforms Markets and Freedom, New Haven: Yale University Press.

Burk, D. L. and M. A. Lemley (2009), The Patent Crisis and How the Courts Can Solve It, Chicago and London: University Of Chicago Press.

Coase, R. H. (1960), "The Problem of Social Cost", Journal of Law and Economics, 3: 1-44.

Cook-Deegan, R. and T. Dedeurwaerdere (2006), "The Science Commons in Life Science Research: Structure, Function and Value of Access to Genetic Diversity”, The International Social Science Journal, 58(2): 299-318.

Demsetz, H. (1967), "Toward a Theory of Property Rights", The American Economic Review, 57(2): 347-359.

Frey, B. (2008), Happiness: A Revolution in Economics, Cambridge: MIT Press.

Frischmann, B. (2012), Infrastructure: The Social Value of Shared Infrastructure, New York: Oxford University Press.

Frischmann, B. (2007) 'Cultural Environmentalism and The Wealth of Networks', University of Chicago Law Review 74: 1083.

Frischmann, B. M. and M. A. Lemley (2007), "Spillovers", Columbia Law Review, 107(1): 257301.

Gordon, W.J. (2010), 'Discipline and Nourish: Construction Commons', Cornell Law Review, 95(4): 733.

Hardin, G. (1968), 'The Tragedy of the Commons', Science, 162: 1243.

Hayes, T. and E. Ostrom (2005), "Conserving The World's Forests: Are Protected Areas The

Only Way?”, Indiana Law Review, 38: 595-617.

Hess, C. and E. Ostrom (eds). 2005. Understanding Knowledge as a Commons: From Theory to Practice, Cambridge, MA: MIT Press.).

Indiana University Bloomington (2008), The Vincent and Elinor Ostrom Workshop in Political Theory and Policy Analysis, [online] Available at: http://www.indiana.edu/ workshop/ [Accessed 12 February 2013].

International Association for the Study of the Commons (2012a), [online] Available at: http://www.iasc-commons.org/ [Accessed 12 February 2013].

International Association for the Study of the Commons (2012b), History, [online] Available at: http://www.iasc-commons.org/about/history [Accessed 12 February 2013].

Lemley, M. A. (2005), "Property, Intellectual Property, and Free Riding", Texas Law Review, 83: $1031-1075$.

Macey, G.P. (2010), 'Cooperative Institutions in Cultural Commons', Cornell Law Review, 95(4): 757.

Madison, M. J., Frischmann, B. M. and K. J. Strandburg (2009), "The University as Constructed Cultural Commons", Washington University Journal of Law \& Policy, 30: 365-403. 
Madison, M. J., Frischmann, B. M. and K. J. Strandburg (2010a), "Constructing Commons in the Cultural Environment", Cornell Law Review, 95(4): 657-709.

Madison, M. J., Frischmann, B. M. and K. J. Strandburg (2010b), “The Complexity of Commons", Cornell Law Review 95(4): 839-850.

Merton, R.K. (1979), 'The Normative Structure of Science' in The Sociology of Science: Theoretical and Empirical Investigations, Chicago, IL: University of Chicago Press, pp. 267-278.

Ostrom, E. (1990), Governing the Commons: The Evolution of Institutions for Collective Action, New York: Cambridge University Press.

Ostrom, E. (1998), "A Behavioral Approach to the Rational Choice Theory of Collective Action: Presidential Address, American Political Science Association, 1997”, The American Political Science Review, 92(1): 1-22.

Ostrom, E. (2000), "Collective Action and the Evolution of Social Norms", The Journal of Economic Perspectives, 14(3): 137-158.

Ostrom, E. (2005), Understanding Institutional Diversity, Princeton, NJ: Princeton University Press.

Ostrom, E. (2007), "A Diagnostic Approach For Going Beyond Panaceas", Proceedings of the National Academy of Sciences, 104(39): 15181-15187.

Ostrom, E. (2009), “A General Framework for Analyzing Sustainability of Social-Ecological Systems”, Science, 325(5939): 419-422.

Pink, D. H. (2010), Drive: The Surprising Truth About What Motivates Us, New York: Riverhead Books.

Reichman, J., Dedeurwaerdere T. and P. Uhlir (forthcoming), Global Intellectual Property Strategies for the Microbial Research Commons, Cambridge University Press.

Reichman J. and P. Uhlir (2003), "A Contractually Reconstructed Research Commons for Scientific Data in a Highly Protectionist Intellectual Property Environment", Law and Contemporary Problems, 66: 315-462.

Samuelson, P. (1954), "The Pure Theory of Public Expenditure", The Review of Economics and Statistics, 36(4): 387-389.

Schweik, C. M. and R. C. English (2012), Internet success: a study of open-source software commons, Cambridge: MIT Press.

Strandburg, K. J. (2009), "Evolving Innovation Paradigms and the Global Intellectual Property Regime", Connecticut Law Review, 41: 861-920.

Uhlir, P.F. (ed.) 2011, Designing the Microbial Research Commons: Proceedings of an International Symposium, National Academies Press.

Von Hippel, E. (2006), Democratizing Innovation, Cambridge: MIT Press. 